\title{
UN⿴囗니스 \\ The protective role of macrophage migration inhibitory factor (MIF) in acute kidney injury after cardiac surgery
}

RWWHAACHEN

Department of

Intensive Care Medicine

Luisa Averdunk ${ }^{1}$, Richard Bucala², Peter Boor ${ }^{3}$, Sonja Djudjaj ${ }^{3}$, Gernot Marx ${ }^{1}$, Christian Stoppe ${ }^{1}$

${ }_{1}^{1}$ Department of Intensive Care Medicine, University Hospital, RWTH Aachen, Germany

2 Department of Internal Medicine, Yale University School of Medicine, New Haven, USA

${ }^{3}$ Institute of Pathology \& Department of Nephrology, University Hospital, RWTH Aachen, Germany

\section{ObJective}

Acute kidney injury (AKI) is a common complication after cardiac surgery [1], which is triggered by inflammation and oxidative stress. Within inflammation, macrophage migration inhibitory factor (MIF) represents a stress-regulating cytokine that may protect from myocardial ischemia-reperfusion (I/R) injury by reducing oxidative stress [2]. We tested the hypothesis, if MIF is also protective against AKI by cytoprotective and antioxidant effects.

\section{METHOdS AND RESULTS}

\section{CARDIAC SURGERY}

\section{HIGH MIF SERUM LEVELS ARE ASSOCIATED WITH REDUCED RISK FOR AKI}

Serum and urine samples were collected from 60 patients scheduled for cardiac surgery with the use of cardiopulmonary bypass. Serum levels of MIF and urinary levels of the tubular injury marker NGAL (neutrophil gelatinaseassociated lipocalin) were quantified by ELISA.

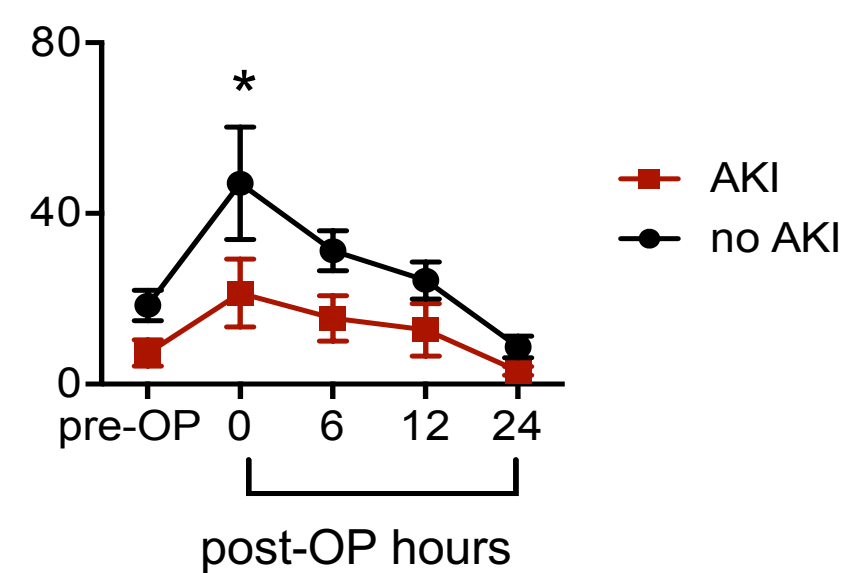

Figure 1: MIF serum levels peaked directly after cardiac surgery. Patients with AKI had significantly reduced MIF levels during the perioperative time course compared to patients without AKI.

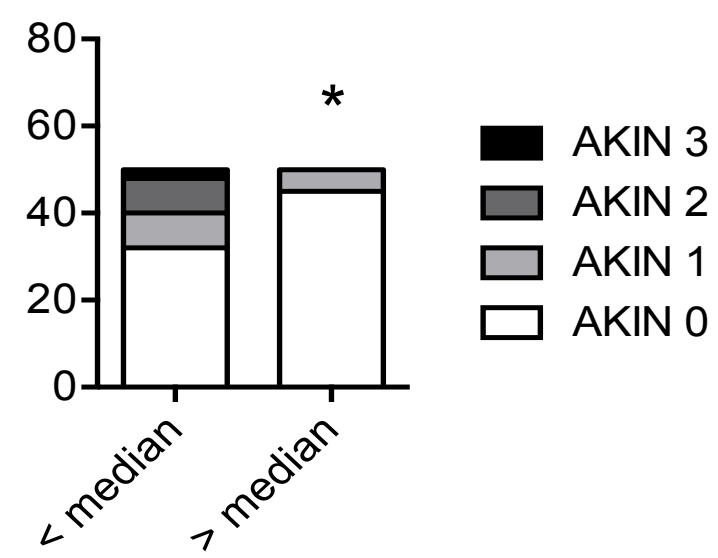

Figure 2: Compared to patients with low postoperative serum levels of MIF (< median), patients with high serum MIF levels showed a reduced incidence of AKI

relative risk reduction $\mathbf{- 7 2 . 7 \%}$ $p=0.03$

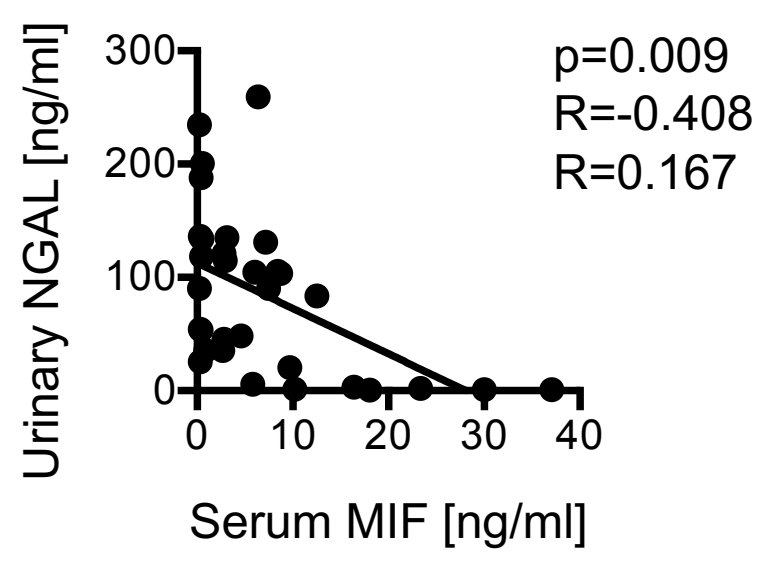

Figure 3: Serum MIF levels inversely correlated with postoperative urinary NGAL levels

Legend:
${ }^{*} \mathrm{p}<0.05,{ }^{* *} \mathrm{p}<0.01$

\section{IN VIVO STUDY OF THE RENOPROTECTIVE ROLE OF MIF}

To confirm the potential renoprotective role of MIF in vivo and to identify potential mechanisms, we compared wild-type (WT) and MIF deficient (Mif-/-) mice subjected to uni- or bilateral renal ischemia and reperfusion.

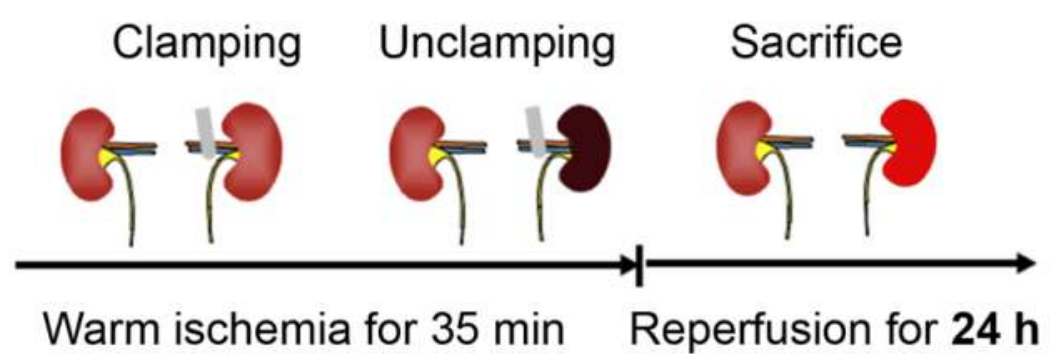

Scheme 1: Experimental setting of AKI by cross-clamping of the renal artery for $35 \mathrm{~min}$ and reperfusion for $24 \mathrm{~h}$ in WT and Mif-/- mice, $\mathrm{n}=5$

Additional experiments (not shown): $6 \mathrm{~h}$ of $\mathrm{I} / \mathrm{R}$, bilateral I/R, rhabodmyolysis

\section{INCREASED SERUM CREATININE IN MIF--I- MICE}

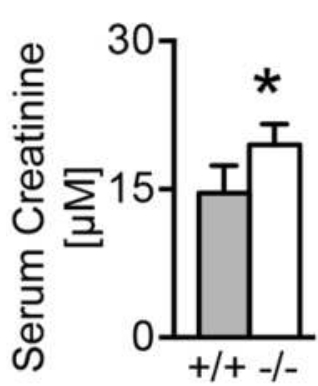

Figure 4: Compared to WT mice, Mif-/- mice suffered from significantly aggravated AKI as shown by higher serum creatinine $24 \mathrm{~h}$ after I/R injury.

\section{CELL DEATH IN MIF/- MICE: NECROSIS, APOPTOSIS AND NECROPTOSIS}

Regulated cell death is a major pathophysiological mechanism of AKI. The number of apoptotic tubular cells was significantly higher in Mif-/- mice compared to WT mice, but overall low. Besides apoptosis, necroptosis and ferroptosis are crucial in AKI [3]. Phosphorylated MLKL is the essential mediator of necroptosis [4]. After $\mathrm{I} / \mathrm{R}$ injury, the number of $\mathrm{pMLKL}$ positive, necroptotic tubuli was significantly higher in Mif-/- mice compared to WT.

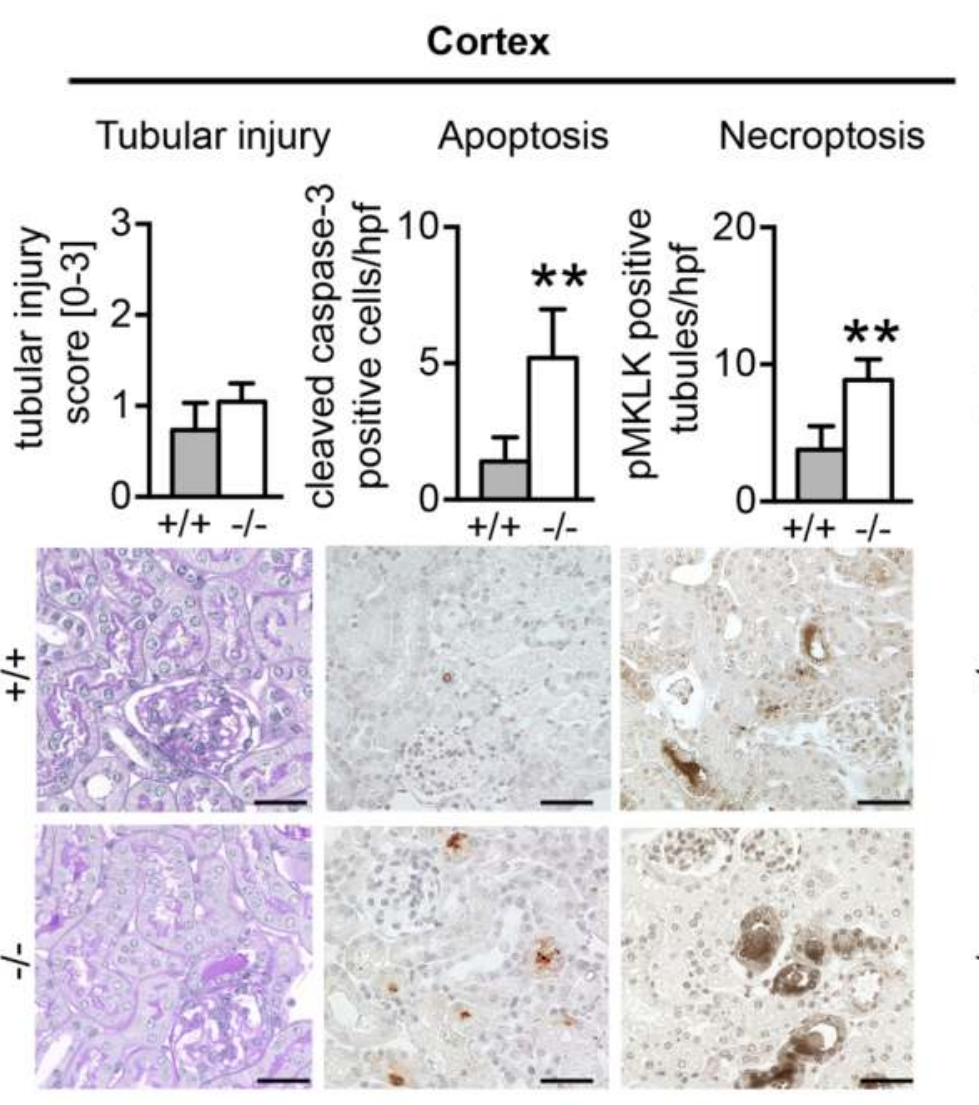

\section{\begin{tabular}{ccc}
\multicolumn{3}{c}{ outer Medulla } \\
\hline Tubular injury $\quad$ Apoptosis Necroptosis
\end{tabular}}

Figure 5: Tubular necrosis quantified by tubular injury score Immunohistochemical staining of apoptotic, cleaved caspase-3 positive cells and necroptotic, pMLKL positive tubuli; pMLKL, phosphorylated mixed lineage kinase domain-like; scale bar corresponds to $100 \mu \mathrm{m}$

\section{MIF REDUCES TUBULAR CELL DEATH IN VITRO}

To assess the potential cytoprotective effect of MIF, tubular epithelial cells (pmTEC) were pretreated with MIF and exposed to hypoxia for $24 \mathrm{~h}(<1 \%$ O2). The release of lactate dehydrogenase $(\mathrm{LDH})$ was quantified.

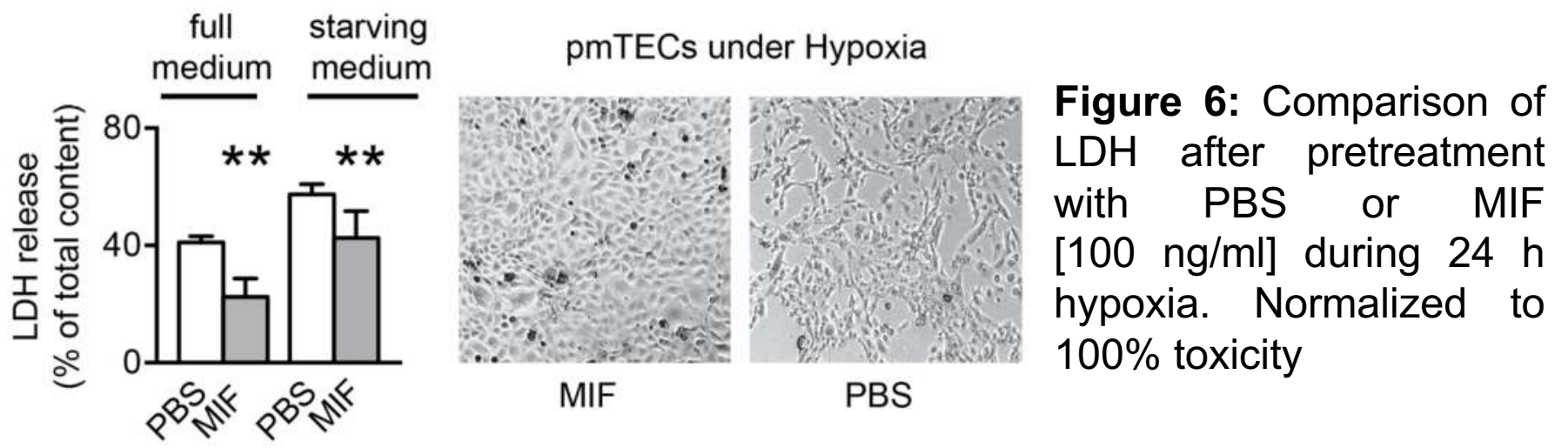

MIF REDUCES OXIDATIVE STRESS LEVELS IN VIVO AND IN VITRO

Oxidative stress is a relevant stimulus for ferroptosis, a regulated cell death pathway. Within ferroptosis, glutathione (GSH) depletion triggers lipid peroxidation. GSH and TBARS, a marker of lipid peroxidation, were quantified.

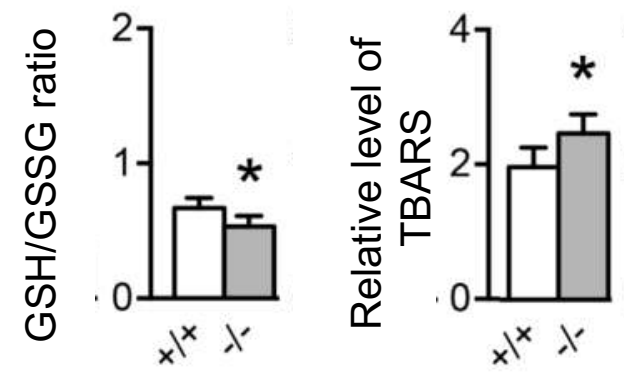

Figure 7: After I/R injury, kidney lysates of Mif-/- mice have reduced levels of GSH and increased TBARS indicating aggravated ferroptosis.
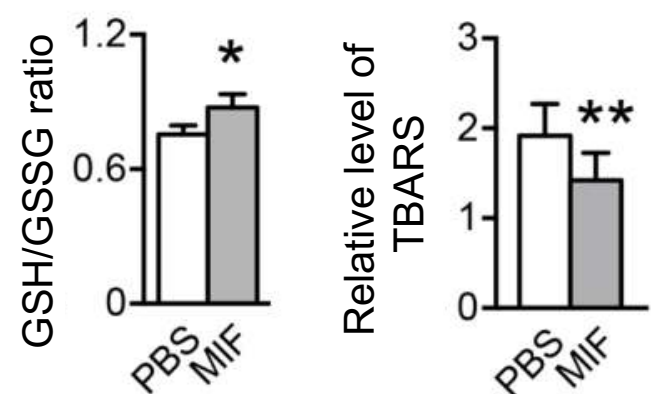

Figure 8: pmTEC were treated with MIF and challenged with hypoxia. MIF treatment preserved GSH and reduced lipid peroxidation (TBARS)

\section{CONCLUSION}

novel, renoprotective function of MIF against AKI after cardiac surgery

- MIF counteracts programmed cell death pathways and oxidative stress

opens therapeutic perspectives to reduce the incidence of $\mathrm{AKI}$

$$
\text { REFERENCES }
$$

1.Brown JR et al. Ann Thorac Surg. 2010; 90(4):1142

2.Miller EJ et al. Nature. 2008; 451(7178):578-82

3. A. Linkermann, Kidney Int. 2016; 89, 46-57

4. Sun L et al. Cell; 2012; 148213-227. 